\title{
É PRECISO SE TRANSFORMAR EM OUTRO PARA SER TU MESMO: EDUCAÇÃO KAINGANG E POLÍTICAS AFIRMATIVAS PARA INGRESSO NO ENSINO SUPERIOR
}

\author{
GEÓRGIA DE MACEDO GARCIA
}

\begin{abstract}
RESUMO
Esse artigo busca compreender a educação a partir de um processo de transformação junto a todos os seres do cosmos, a partir da episteme do Povo Kaingang e do conceito êg jykre. A etnografia traz formas de ensinar e aprender que acontecem no caminhar entre as instituições de ensino superior e os territórios indígenas junto a mulheres estudantes da Universidade Federal do Rio Grande do Sul e três kujá (pajés) Kaingang. 0 esforço etnográfico está em perceber uma educação que acontece na relação com a instituição de ensino superior (aqui pensada como um ser com a marca clânica kamê) a partir das abordagens da Antropologia da Aprendizagem e da Ciência Kaingang, que possui uma episteme organizada em noções duais de conhecimento, embasada nas marcas clânicas Kamēe Kanhru, também chamadas de rá tẽje rá ror. Assim, aprender está relacionado às ideias de complementariedade e captura de alteridades potentes. Para tanto, também trago a categoria tãn e a compreensão da humanidade e da potência que perpassa todos os seres do cosmos. Com isso, pretendo contribuir para as reflexões sobre as políticas afirmativas desde uma perspectiva do encontro de diferentes ciências.
\end{abstract}

\author{
PALAVRAS-CHAVE \\ Educação; Xamanismo; Políticas Afirmativas; Povo Kaingang.
}

\section{IT IS NECESSARY TO BECOME ANOTHER TO BE YOURSELF: KAINGANG EDUCATION AND AFFIRMATIVE ACTIONS FOR THE ENTRANCE TO HIGHER EDUCATION}

\begin{abstract}
This article seeks to understand education based on a transformation process along with all beings from the cosmos, from the Kaingang People's episteme and the êg jykre concept. Ethnography brings ways of teaching and learning that take place while walking between the higher education institutions and the indigenous territories along with female students at the Federal University of Rio Grande do Sul (UFRCS) and three Kaigang kujás (shamans). The ethnographic effort is to perceive an education that takes place in the relationship with the higher education institution (here, thought as a being with the clan mark kame) from the approaches of Anthropology of Learning and Kaingang Science, which has an episteme organized on dual notions of knowledge, based on the clan marks Kamẽ and Kanhru, also called rá tẽjand rá ror. Thus, learning is related to the ideas of complementarity and the capture of potent alterities. To this end, I also bring the tãn category and the understanding of humanity and the power that pervades all beings in the cosmos. Hence, I intend to contribute to the reflections regarding affirmative actions from a perspective of the encounter of different sciences.
\end{abstract}

KEYWORDS

Education; Shamanism; Affirmative Actions; Kaingang People.

IL FAUT DEVENIR UN AUTRE POUR ÊTRE VOUS-MÊME: ÉDUCATION KAINGANG ET ACTIONS POSITIVES POUR L'ENTRÉE DANSL'ENSEIGNEMENT SUPÉRIEUR 


\section{RÉSUMÉ}

L'objectif de cet article est comprendre l'éducation à partir d'un processus de transformation avec tous les êtres du cosmos, basé sur l'épistème du peuple Kaingang et le concept de êg jykre. L'ethnographie apporte des formes d'enseignement et d'apprentissage qui se déroulent en marchant entre les établissements d'enseignement supérieur et les territoires autochtones avec des étudiantes de l'Université fédérale de Rio Grande do Sul (UFRGS) et trois kujás Kaigang (chamans). L'effort ethnographique est de percevoir une éducation qui se déroule dans la relation avec l'établissement d'enseignement supérieur (ici, pensé comme un être avec la marque clanique kame) à partir des approches de l'Anthropologie de l'Apprentissage et de la Science Kaingang, qui a une épistèmè organisée sur des notions de connaissance, basées sur les marques claniques Kamẽ et Kanhru, également appelées rá tẽj et rá ror. Ainsi, l'apprentissage est lié aux idées de complémentarité et de capture d'altérités puissantes. À cette fin, j'apporte également la catégorie tãn et la compréhension de l'humanité et du pouvoir qui imprègne tous les êtres du cosmos. Ainsi, j'ai l'intention de contribuer aux réflexions sur les actions positives dans une perspective de rencontre de différentes sciences.

\section{MoTS-CLÉS}

Éducation; Chamanisme; Actions positives; Le peuple Kaingang.

\section{ES NECESARIO VOLVERSE OTRO PARA PODER SER UNO MISMO: ENSEÑANZA KAINGANG Y POLIITICA DE AFIRMACIÓN PARA EL INGRESO EN LA ENSEÑANZA SUPERIOR}

\section{RESUMEN}

Este artículo pretende comprender la educación desde un proceso de cambio junto con todos los seres del cosmos, desde la episteme del pueblo kaingang y del concepto êg jykre. La etnografía trae formas de enseñar y aprender que se dan en el caminopor las instituciones de la enseñanza superior y los territorios indígenas, junto con mujeres estudiantes de la Universidad Federal de Rio Grande do Sul y tres kujá (chamanes) kaingang. El esfuerzo etnográfico está en percibir una educación que se produce en la relación con la institución de enseñanza superior (aquí pensada como si fuera un ser con la marca clánica Kamê) abordada desde la antropología del aprendizaje y de la ciencia kaingang, que tiene una episteme organizada en nociones duales de conocimiento, basada en las marcas clánicas Kamê y Kanhru, también conocidas como rá tẽje rá ror. Así, el hecho de aprender está vinculado a las ideas de complementariedad y potentes alteridades. Por lo tanto, también se aporta la categoría tãn y la comprensión de la humanidad y de la potencia que sobrepasa a todos los seres del cosmos. Con ello, pretendo contribuir en las reflexiones de políticas afirmativas desde una perspectiva del encuentro de diferentes ciencias.

PALABRAs CLAVE

Educación; Chamanismo; Politicas de acción afirmativas; Pueblo Kaingang. 


\section{ÊG JYKRE, "PROSEANDO PARA COMEÇAR"}

Inicio, como muito ouvi em campo, "proseando" (conversando) com o leitor sobre as possíveis traduções para êg jykre. Era dezembro de 2017 e eu estava na Terra Indígena Goj Vêso ${ }^{1}$. Acontecia o Acampamento Terra Livre Sul (ATL Sul) que reuniu lideranças espirituais e políticas, jovens e crianças do Povo Kaingang, Xokleng e Mbyá-Guarani.

Consegui um carro emprestado e pegamos a estrada, partindo com os primeiros raios de sol do amanhecer da cidade de Porto Alegre: eu, Ana Letícia (na época, minha colega de mestrado), Angélica Kaingang (na época, estudante de Serviço Social na Universidade Federal do Rio Grande do Sul - UFRGS), Woie (marido de Angélica) e a Naiane (filha de Angélica). Viajamos em torno de sete horas até o município de Iraí (RS), chegando no meio da tarde, quando as discussões já estavam acontecendo no grande ginásio. Findadas as conversas do dia, fomos todos nos banhar no Rio Uruguai e, no cair da noite, as estrelas cadentes passavam riscando a imensidão azul escuro que nos abraçava. Após a janta, resolvi caminhar até à frente da escola.

Vi o kujá (pajé) Kaingang Pedro sentado em uma mureta que tinha por ali. Estava sozinho, contemplando a noite e o movimento dos adultos, jovens e crianças que agora, depois de um dia de reunião, conversavam e brincavam entre si. "Oi Pedro!", exclamei. Percebendo que ele não me reconhecia continuei, "Eu sou uma daquelas que tira as fotos dos encontros da Rede de Saberes Indígenas na Escola, lembra de mim?". Pareceu-me que ele não lembrava, mas abriu um sorriso e me abraçou, convidando-me para sentar. Com a água ainda quente na térmica, comecei a fazer um chimarrão que fez a palavra circular entre nós.

"E os seus pais não vêm?", perguntei. "Ah, nós vamos pegar eles amanhã", fez uma longa pausa e continuou. "Eu já posso fazer os trabalhos. Eu posso fazer, mas o pessoal ainda tem o meu pai como referência. E dai, como perguntam muito, vamos buscar amanhã. Mas olha, eu tenho 58 anos e ainda venho aprendendo com o meu pai", falou. "Nossa, 58 anos e ainda tá aprendendo!", interrompi fazendo ele gargalhar com o meu comentário. "É, ainda estou aprendendo. Eu me sinto, eu acho, como um psicólogo desses de vocês. Fico só observando como os meus kamē e os meus kanhru agem", comentou e fez outra pausa para tomar sua cuia de chimarrão.

"Vendo o debate hoje, penso que a gente tem que cuidar para não falar só da política dos brancos. Tem a nossa também e que vem das marcas", continuou. Comentei que as conversas do dia tinham sido voltadas a pensar as propostas do governo atual. "É, pode

\footnotetext{
${ }^{1}$ A Terra Indígena Goj Vêso fica localizada no município de Iraí, Rio Grande do Sul - BR. O território foi retomado em 17 de julho de 2016 quando ocuparam as instalações do antigo Colégio Agrícola da Universidade Federal de Santa Maria.
} 
ser", falou. "Mas as nossas marcas são importantes e devem servir de motivação para os Kaingang e para os fóg (não indígenas) que querem trabalhar com a gente", completou.

Conversei com o Pedro novamente por telefone durante a organização da III Mostra de Cinema Tela Indígena (2018)². Ele participaria de uma atividade junto com a Cristine Takuáa que sugeriu o nome "Arandu Porã: Sabedoria Mbyá-Guarani" para se referir a sua contribuição na conversa. Mas ainda precisávamos de uma palavra em Kaingang que desse título à atividade. Conversando com Ana Letícia, ela me lembrou da palavra jykre. "Alguns falam que é sabedoria, mas temos que pesquisar essa tradução", me recordo que ela comentou.

"Oi Pedro! Aqui quem fala é aquela que tira as fotos dos encontros do Saberes", me recordo que falei quando o Pedro atendeu a minha ligação. "Ah minha amiga, lembro sim", ele respondeu. Fiz o convite contando sobre a atividade e disse que precisávamos pensar em um nome. Que tinha surgido a ideia de chamar de jykre. "O quê?", ele perguntou, provavelmente, não entendendo a minha péssima pronúncia. Depois de eu repetir muitas vezes, ele continuou. "Ah, acho que tu tá falando jykre. Acho muito bom. Jykre significa pensamento em conjunto, plano em conjunto. Como estamos fazendo isso juntos, parece bom".

Dias depois continuei aprendendo sobre o jykre. Douglas Kaingang e eu conversávamos sobre a nossa experiência no programa de mestrado em Antropologia Social. Comentei que Pedro tinha confirmado a participação durante a Mostra. O nome da atividade tinha ficado "Arandu porã e Jykre: sabedoria Mbyá-Guarani e Kaingang". Ele me olhou e disse. "Êg jykre". "Como assim?", questionei, ao passo que ele começou a me explicar que êg designa o plural. É traduzido como o pronome "nós" e "nosso". E jykre (o conhecimento, a sabedoria) sempre se faz com mais de um. Com o outro. Nunca sozinho. É o "nós". Pelo que vinha aprendendo com os velhos, o jykre era a base da vida Kaingang.

Durante o VIII Encontro de kujá4, 2018, retomei esse assunto com Pedro. Ele ainda trouxe outras traduções. Disse que jykre seria plano, pensamento em conjunto. Com todos: com as outras pessoas e com os animais. Não adiantava ficar sozinho. Tinha que ser em conjunto, como a mãe dele fazia. Foi com ela que aprendeu sobre compartilhar, sobre dividir.

\footnotetext{
${ }^{2}$ Mostra de cinema indígena que acontece na cidade de Porto Alegre desde 2016.

${ }^{3}$ Cristine é Maxakali, filósofa, educadora e artesã indígena, vive no território Mbyá-Guarani Rio Silveira, litoral de São Paulo. Estuda há mais de 10 anos plantas medicinais. É professora da Escola Estadual Indígena Txeru Ba'e Kuai' e auxilia nos trabalhos espirituais na casa de reza.

${ }^{4}$ Os encontros de Kujá (pajé) acontecem de dois em dois anos, no território Kaingang do Morro do Osso, Porto Alegre/RS.
} 
"Mas daí se tu é kamē tu aprende com a tua mãe que é rá ror ${ }^{5}$ ? Ou com teu pai?", perguntei, ao passo que ele respondeu:

É quando eu estava aprendendo. Assim, conforme a tua pergunta, tá? Eu aprendia só com ela. Daí, agora, depois que eu entendi, daí eu posso aprender mais ainda com qualquer um. Com qualquer marca. Mas eu tô notando, nos trabalhos, não é que a gente tá se exaltando. No trabalho eu tô vendo que todos querem perguntar comigo e me dar ideia e receber a minha ideia. Todos. Então, a minha obrigação é eu passar para aquele que quer aprender. (...) Então, eu não vou me acanhar. Eu vou me soltar. Se puderem me ocupar. Daí eu não escolho, porque eu já sou formado, né. Kujá. Por causa disso. Mas quando eu tô aprendendo, eu deveria usar mais o rá ror comigo do que o rá tẽj. Porque daí com o rá tj, daí nós brigamos (Entrevista com Pedro Garcia, novembro de 2018).

"Por que é parecido?", perguntei. "Porque disputa, né. Disputa na ideia". "Ah, sim", suspirei. "E com o rá ror já fecha. A gente disputa, disputa, mas a gente fecha junto. E se abraça", ele continuou, fazendo com que ríssemos juntos. "É, com rá ror é assim. Então é conforme o Sol e a Lua, né. Porque a Lua e o Sol brigaram, mas eles trabalham juntos", me explicava. "Ah sim... porque, depois que chove tem que vir o Sol para...", comecei a falar. "Tem que vir o Sol para aquecer, né? Porque só chuva, chuva também mata.", completou o Pedro, finalizando a nossa conversa.

Essa foi a primeira vez que eu ouvi sobre as marcas e o Sol e a Lua (história que será retomada no decorrer da escrita). O Sol, kamē / rá tēj e a Lua, kanhru / rá ror. O Pedro (que é da marca kamê) traz a ideia do sol e a lua trabalharem em conjunto. Eles podem brigar, pois são diferentes, mas eles se acertam, pois a diferença ensina. A diferença complementa. Na sua fala, também diz já ser "formado Kujá", o que the permite trabalhar com as duas marcas. Porém, quando estava aprendendo, ficava junto a sua mãe, kanhru / rá ror.

Os casamentos ideais são aqueles onde o casal tem marca contrária e a descêndencia das marcas kamē e kanhru se dá de forma que a criança sempre terá a marca contrária a sua mãe. A fertilidade vem da diferença e, durante o período de gestação, a mulher cria um corpo que tem marca oposta à sua. A criança cresce e se desenvolve de forma saudável porque o corpo da mãe a guarda e a faz crescer de forma fértil. Antes de prosseguirmos, ainda é importante pontuar que os kujá ensinam que as marcas não são fixas nos corpos, informação relevante para compreender a aprendizagem como um ato de transformação. O outro, diferente de mim, está como uma alteridade potente. Que me ensina, mas que - no excesso - também pode ameaçar o meu corpo.

\section{MÉTODO}

\footnotetext{
${ }^{5}$ Kamē ou rá tēj e Kanhuru ou rá ror são as metades clânicas do Povo Kaingang. Também conhecidas como a marca cumprida e a marca redonda, respectivamente. Todos os seres do cosmos possuem uma das marcas. Possuir uma marca implica possuir um tãn, como veremos ao longo do texto.
} 
Neste artigo há algumas das reflexões que tracei na minha dissertação de mestrado. A experiência etnográfica junto a mulheres Kaingang aqui descrita demonstra formas de estar, ensinar e aprender que estão presentes na UFRGS desde as políticas afirmativas. O esforço etnográfico está em perceber uma educação que acontece na relação com a instituição de ensino. Para isso, aprofunda-se na categoria tãn e, portanto, na compreensão da humanidade e da potência que perpassa todos os seres do cosmos.

Demorou um tempo para eu perceber que jykre daria sentido não só para a base do que me parece ser Educação a partir da episteme Kaingang de conhecimento, mas também ao meu método de pesquisa e aos meus referenciais teóricos. Afinal, se êg jykre tem a ver com fazer conhecimento em conjunto, como poderia me colocar fora desse processo? Inicio por uma discussão metodológica.

Caminhar junto a aprendizes Kaingang foi também o meu processo de aprendizagem enquanto antropóloga. Para Goldman (2003), o trabalho de campo é parte do processo de educação do etnólogo, tendo a potencialidade de modificar o pesquisador e dizer que a etnografia é um processo de observação do comportamento, seria diminuir a experiência de fazer cultura junto ao outro.

Durante a escrita da dissertação me perguntava como refletir sobre o que aprendi na convivência a partir de uma discussão antropológica. O aprendizado não havia sido linear como esse momento de escrita me parecia pedir. Assim, segui o conselho de meu orientador que me questionou por que não começava da forma como a educação Kaingang se apresentava para mim: ir fazendo, experimentando, me relacionando com a minha escrita.

E, assim, fui experimentando as palavras e as formas de costurar as diversas localidades pelas quais passei até que escrevi um primeiro esboço que tinha páginas e páginas de descrições das experiências que tive ao lado das crianças, dos jovens e dos adultos do Povo Kaingang. Após, fui articulando a teoria antropológica da aprendizagem e etnológica Kaingang e refletindo sobre essas experiências que, nesse ato de voltar ao vivido, tornavam-se etnografia (INGOLD, 2016). Escrevi. Imprimi. Li. Rabisquei. Reescrevi. E assim por diante. O formato e a ordem escolhida foram propondo-se até o momento em que precisei entregar a dissertação. Agora, mais uma vez, coloco-me nessa experiência de retomar o vivido e o escrito, para elaborar este artigo.

Ingold (2016) escreve sobre a observação participante como principal método de pesquisa da Antropologia e que necessita de tempo, de espera, de um movimento de investigação que se desenrola a partir da percepção e ação do antropólogo junto aos movimentos dos outros. Propõe o termo correspondência para designar essa composição de movimentos que é feita da observação e da participação. Para o autor, observar significa olhar o que está acontecendo ao redor, e também escutar e sentir. Participar, por sua vez, 
seria fazer dentro do contexto da atividade que se está preocupado em entender. Ao lado e junto com as pessoas e com as coisas que captam a sua atenção (INGOLD, 2016).

Colette Pétonnet (2017) sugere como método uma "observação flutuante". Essa consiste em seguir disponível em todas as circunstâncias, sem mobilizar a atenção sobre um objeto específico. É preciso deixar a atenção flutuar para que as informações a penetrem sem filtro, até o momento em que pontos de referência e de convergências comecem a surgir e seja possível descobrir regras subjacentes (PÉTONNET, 2017).

Para mim, não bastava nem só observar, nem só flutuar, nem só participar. Penso que "fazer em conjunto" unia esses três verbos: Flutuar. Observar. Participar. Mais do que qualquer outra disciplina nas ciências humanas, para a antropologia, o conhecimento surge a partir da vida vivida com os outros (INGOLD, 2016) e, inspirada pelas ideias de Strathern (2013), Abu-Lughod (2000) e George Marcus (2001) e pela possibilidade de uma etnografia multilocalizada, me submeti ao que parecia essencial para compreender a complexidade da episteme Kaingang no que se refere à educação: estar junto na caminhada.

Isso fez com que muitas das minhas conversas não fossem gravadas. Como pontua Sérgio Baptista da Silva (2013) as técnicas de registro devem ser avaliadas a partir do contexto dos encontros, não prejudicando o método etnográfico. Aprendi muito em silêncio. Com o tempo, comecei a perguntar. Anotar. Perguntar novamente. Esperar, deixando-me levar. Assim, algumas das falas das pessoas com quem conversei foram gravadas e são aqui transcritas. Mas a maioria delas é construída a partir das minhas anotações.

Aproveito para apresentar Angélica Domingos, natural da Terra Indígena do Votouro (norte do Estado do RS) minha primeira professora Kaingang. Quando a conheci, em 2015, era estudante do curso de Serviço Social na UFRGS. Atualmente, realiza seu mestrado na mesma instituição. Ela, junto com meu orientador, passou a ser minha tutora. Percebendo a minha curiosidade, me chamou para caminhar com ela, mostrando-me o mundo para que eu também pudesse olhar, ouvir e sentir (INGOLD, 2010).

Ao longo da escrita ficará claro que coisas que aprendi cronologicamente antes apenas fizeram sentido a partir de experiências posteriores. Construí uma forma de pensar e escrever que faz o leitor ir para diferentes localidades, no tempo e no espaço. A etnografia busca trazer um aprender na prática que acontece (LAVE, 2015) desde uma perspectiva que está baseada nas marcas Kamēe Kanhru.

A ideia de um "campo de trabalho" que se dá em um local distante e com fronteiras delimitadas vem sendo colocada em questão (FONSECA, 2017). A Universidade faz parte de um universo que nos é partilhado. Por outro lado, as histórias que me eram contadas, as experiências de vida relacionadas a esta instituição de ensino me deslocavam imensamente. Existem múltiplas formas de pensar a formação de uma pessoa. Algumas estão relacionadas 
com o início e o fim de determinados cursos. Outras estão relacionadas ao processo de toda uma vida. Ao processo da manutenção de um corpo.

Como observou certa vez Angélica, deslocar-se para estudar nesta instituição é também uma forma de continuar caminhando, como os seus ancestrais faziam. A universidade é um local de formação, como também um lugar de passagem para transformar e se deixar transformar. Não há um só ponto de chegada. Talvez as mudanças de caminho tampouco possam ser consideradas enquanto mudança (INGOLD, 2015).

\section{REFERENCIAIS TEÓRICOS}

Proponho pensar o conceito de "aprendizagem" como transformação. A transformação, por sua vez, não é algo que acontece de uma hora para outra como poderia, primeiramente, saltar às nossas mentes, mas algo que acontece ao longo de toda a vida. Começa com o nascimento e termina com a morte. Com 58 anos, ainda se está aprendendo, como lembrou Pedro.

Para Lave (2015), pensar Antropologia da Aprendizagem, ou seja, pensar como a aprendizagem acontece, é menos sobre o que acontece em um contexto educacional e mais sobre como "aprender na prática" é constituído por participantes em movimento que estão atravessando e lidando com contextos nos quais eles participam. A aprendizagem (a transformação), nesse sentido, faz parte da vida cotidiana que é composta pelos encontros, pelas dificuldades, pelas conquistas, pelas observações e perguntas de cada um dos dias de nossas vidas. Recordo que a Dra. Ana Gomes (GOMES, 2018) ponderou, na banca de defesa de dissertação de minha colega Ana Letícia, que educação é relação.

Relação é um conceito abstrato por si só (não é algo que se vê, mas algo que se infere). Nesse sentido, para que elas se tornem visíveis, devem ser objeto de trabalho intelectual em uma ecologia atenta aos seres tal como emergem e se transformam (STRATHERN, 2016). Рara pensar educação enquanto relação era preciso que eu mergulhasse na experiência de ser educada por pessoas indígenas Kaingang. Participar e mudar de lugar na participação. Buscando entender o que poderia ser educação, relação, transformação.

Com isso, é importante esclarecer que não pretendo aqui dizer o que é educação indígena, nem o que são ou como agem e se relacionam as pessoas indígenas com as quais eu convivi. Não se pode confundir o que estou escrevendo com o que os Kaingang são. A cultura não é o que o outro é. Aliás, enquanto lia Mabilde [1836-1866] (1983), pensava sobre a descrição das atividades da vida dos Kaingang que o autor trazia. Como organizavam a caça de papagaios. Aos silêncios dos alojamentos e modos de falar. O respeito às lideranças. Como preparavam aquilo que chama de correrias e suas estratégias. Como quebravam os 
galhos por onde passavam para marcar o caminho. Este autor, ao contar a sua experiência, referia que o povo kaingang teria uma certa violência "natural" nos seus atos.

Primeiro fiquei apenas impressionada com os relatos e encantada com essa convivência que descrevia um modo de vida que parecia não ter tanta "interferência" dos não indígenas. Após, fiquei me perguntando se essa descrição consistia, de fato, no que os Kaingang eram? Como poderia ser se essa escrita já estava sendo realizada a partir do contato? Da relação com o outro? Não só do antropólogo, mas, por exemplo, da violência dos bugreiros investida contra os povos originários da região do Rio Grande do Sul em função dos conflitos de território?

Descrevo aqui o meu mergulho na experiência ao lado de pessoas indígenas Kaingang. A cultura é a relação. É, mais do que isso, a invenção do que faço para dar significado ao outro que me interpela (WAGNER, 2017 [1975]). Não é o que os estudantes indígenas são ou, mais especificamente, o que as pessoas com as quais eu trago as histórias que compartilhei são. Tudo que aqui trago é a minha relação com eles e a invenção, minha e deles, das motivações para se movimentar, aprender e ocupar a Universidade. Deles, pois muitas vezes interpelados por mim. Minhas, pois a posição de pesquisadora me convoca a escrever.

Roy Wagner (2017 [1975]) propõe pensar desde uma perspectiva da objetividade relativa. Isso implica reconhecer que para a compreensão de uma cultura é necessário envolver dois fenômenos humanos. Ou seja, uma relação intelectual entre eles e não a análise ou exame de um pelo outro. Com essa interpretação, o autor nos convoca a repensar a ideia de cultura como algo concreto e que se torna visível no encontro, mas sim como a extensão desse encontro. A aprendizagem e a objetificação da cultura acontecem ao mesmo tempo fazendo com que o conceito de cultura seja uma alegoria. Ou seja, uma imagem que representa outra que está imersa em significados. Significados que estão imersos na perspectiva daquele que escreve. São diversas metáforas em relação ${ }^{6}$.

Com isso, pontuo novamente que vou contar o que aprendi sobre educação Kaingang na medida em que eu me submeti ao que parecia essencial a essa forma de aprender: caminhar. Fazer perguntas. Observar. Estar junto.

Reflito sobre a minha etnografia a partir das abordagens da antropologia da aprendizagem (INGOLD, 2015; LAVE, 2015) e pelos processo próprios de educação do Povo Kaingang. A aprendizagem a partir da captura de alteridades potentes e da complentariedade, nos territorios indígenas ou nas cidades, baseia-se na diferença

\footnotetext{
${ }^{6}$ Roy Wagner, em 2012, em uma entrevista para a Folha de São Paulo, pontua que uma das lições de Castañeda é que a metáfora é também uma piada. Uma distorção irônica de palavras e perspectivas. Ambas metaforizam uma mesma relação, mas partem de pontos de referência distintos.
} 
mitológica de origem do Povo Kaigang introduzida pelo nascimento dos gêmeos Kamē e Kanhru (BAPTISTA DA SILVA, 2002). Assim, a ciência deste povo apresenta uma episteme dual a partir das marcas kamē ou rá tēj e kanhru ou rá ror. Todos os seres do cosmos possuem uma dessas marcas que também são representadas no grafismo como um traço cumprido (kamē/rá tejj) e outro redondo (kanhru/rá ror).

Os kujá (pajés Kaigang) são os grandes conhecedores das histórias que desvelam essas lógicas. Foi a Angélica e os kujá Pedro e Iracema quem me mostraram que, seja no território ou na cidade, esse conhecimento se perpetua e se mescla às outras epistemes. Como sugere Langdon (2010), há uma multiplicidade dos fenômenos xamânicos, nos quais existem pouca unidade, muita fragmentação e fronteiras imprecisas (LANGDON, 2010 apud GUPTA; FERGUSON, 2001, p. 165), o que me leva a refletir que o debate em torno das políticas afirmativas não se dá apenas a partir do encontro de diferentes culturas, mas em torno das diferentes ciências.

\section{O POVO KAINGANG E A ABERTURA DE VAGAS NA UFRGS}

Os Kaingang, junto com os Xokleng, compõem o grupo de sociedades indígenas Jê Meridionais, pertencendo, do ponto de vista linguístico, ao Tronco Macro-Jê. Constitui um dos mais populosos povos indígenas do Brasil, calculado em 37 mil pessoas (IBGE, 2010). Habitantes do Planalto Meridional Brasileiro, seus territórios estão em regiões altas, de florestas de araucárias, de pinheiros e de campos altos do Sul do Brasil.

Como mostra Clementine Márechal (2015), a mobilidade é uma das bases da territorialidade Kaingang fazendo com que o território se construa também a partir de viagens e movimentos. Atualmente podemos ver a presença dos Kaingang nos estados do Rio Grande do Sul, Santa Catarina, Paraná e o sul de São Paulo, habitando territórios demarcados, retomada de territórios, as cidades e os centros urbanos. Pontuo aqui que para pensar educação é preciso perceber que o movimento entre os diferentes territórios e a própria retomada destes ${ }^{7}$ são essenciais ao aprendizado.

Como pontua Ana Letícia Schweig (2018), não há como pensar em educação, sem pensar em território. Essa perspectiva faz com que seja necessário ampliar as noções de território indígena para além das terras demarcadas, considerando terra indígena todos aqueles espaços em que os indígenas estão, em determinado momento, ocupando, como

\footnotetext{
${ }^{7}$ Retomar um território não é apenas ocupar uma terra, mas dar a vida de volta a ela. Na Terra Indígena de Rio dos Índios (terra com demarcação paralisada há 14 anos), em maio de 2018, o Cacique Saci mobilizou a plantação de 4 mil mudas de araucárias em uma ação que envolveu cerca 500 indígenas Kaingang e Guarani.
} 
coloca Osias Sampaio (2017). Nesse mesmo sentido, apontam as lideranças Kaingang ao falarem que estar na universidade é demarcar este território.

A discussão quanto à democratização do Ensino Superior tramitou durante 13 anos no Congresso Nacional. O projeto de Lei 180/2008 apenas foi assinado e sancionado pela Presidenta da República em 2012 na forma de Lei 12.711. A UFRGS inicia institucionalmente o debate quanto à adoção de ingresso por cotas em 2004, a partir do processo de apreciação da reforma universitária que foram potencializados por projetos de extensão universitário.

Em 2008, aprovada a proposta pelo Conselho Universitário (CONSUN), institui-se o processo de democratização de acesso na UFRGS. A intitulada Lei de Cotas estabelece a obrigatoriedade da reserva de vagas nas Universidades e Institutos Federais. Na UFRGS, inicialmente, havia duas comissões de acompanhamento dos estudantes que ingressavam pelas políticas afirmativas, sendo que uma se dedicava exclusivamente aos estudantes indígenas. Por decisão do CONSUN (n. 268/2012), fundiram-se as comissões, instituindo-se a Coordenadoria de Acompanhamento do Programa de Ações Afirmativas (CAF), órgão de gestão ligado à Pró-Reitoria de Coordenação Acadêmica que, por meio da articulação com Unidades e Comissões de Graduação, acompanha os estudantes cotistas. Conforme o relatório da CAF de 2016, no período de 2008 a 2016 havia 70 estudantes Kaingang e 12 Mbyá-Guarani regularmente matriculados.

\section{A CONSTITUIÇÃO DA PESSOA}

Era o segundo dia do VIII Encontro de kujá e o cacique falava ao microfone que as pessoas deveriam se dividir em pequenos grupos para que continuassem conversando sobre as questões que estavam sendo debatidas ali, como Saúde, Educação, Território. Estava um dia muito quente e o calor, misturado com o marrom avermelhado da terra, fazia parecer que tudo acontecia de forma lenta. Aos poucos algumas pessoas começaram a pegar suas cadeiras e formar uma roda em torno dos kujá. Parecia-me que as pessoas que, ali na volta, se acomodavam, esperavam que eles tomassem a palavra e alguma atividade começasse, mas isso não aconteceu. Comendo sacolé ${ }^{8}$, eles apenas observavam o movimento do galpão e conversavam com aqueles que chegavam perto dos seus ombros.

\footnotetext{
8 "Sacolé" é como chamamos no Rio Grande do Sul aquela espécie de sorvete que consiste em um suco de fruta colocado dentro de um saquinho e, após, congelado. Em Belém é chamado de "chope" e na Bahia de "geladinho".
} 
"E aí Pedro, está esperando virem te fazer pergunta?", questionei me sentando na cadeira que trouxe comigo. Rindo, me respondeu que sim, estava esperando. "Olha, então eu tenho umas perguntas para te fazer", falei. "Oh que bom, então pode fazer"9.

"Pedro, dessa vez eu queria gravar, tu te importa?", perguntei, meio sem graça. "Não, pode colocar aí", respondeu sem parecer se importar comigo. Liguei o gravador do celular e o posicionei no canto da mesinha embutida da cadeira que ele estava sentado. Peguei também o meu caderninho de bolso e o apoiei na minha perna, começando anotações e desenhos.

Contei que queria saber mais sobre as marcas. Que tinha ouvido falar, tanto em conversas com os Kaingang, como também lendo alguns pesquisadores, que o Kamē o Kanhru tinham ficado embaixo da terra depois de uma grande tempestade e, depois de um longo período, sairam de um buraco que se formou. O Kanhru machucou o pé nas pedras, mas que ficou tudo bem porque elas curam. Que eles foram aprendendo com os animais e também que foram dando nomes às coisas a partir das marcas, fazendo o mundo novamente. Continuei falando que queria entender o que era essa diferença do Kamē e do Kanhru e, quando parei de tagarelar porque não sabia mais para onde ir e percebendo que eu já deveria ter parado há muito tempo, ele calmamente tomou a palavra ao passo que eu baixei a cabeça e comecei a desenhar o que ele falava no caderninho que levava comigo:

Pedro: "É diferente por causa do Sol. É que o Sol e a Lua... é... Tem aquela história também que fala assim: o Sol e a Lua, em uma época, eles brigaram. Os dois brigaram e daí separaram longe um do outro. E daí, a Lua apanhou do Sol. E daí a Lua chorou. A Lua chorou e derramou lágrimas. E no derrame da lágrima, fez a formatura de todos os seres"10.

Eu: "Com a lágrima?", interrompi desenhando lágrimas que caíam da Lua já desenhada.

Pedro: "É, com a lágrima. Em uma época que não tinha chuva. Daí vem aqueles, como que se diz? De noite, aquele ar que molha."

Eu: "A geada, que chamam."

Pedro: "É."

Eu: "Hm... isso é da Lua chorando"

Pedro: "É, é da Lua. Só com aquilo. Quando ele separou do Sol ele chorou. E daí começou. Continuou ali. Daí hoje eu vejo que... Porque a Lua, ela é a parte rá ror. Kanhru. E o Sol é da parte do kamè. Rá te[j. E o Sol é muito brabo. O Sol, ele tem só previsão de matar. Ele seca. Ele elimina. Ele vai matando. Só com o calor. Então, daí, para mim significou certo, né. O Sol é da parte do rá tẽj" Eu: "Ah..."

\footnotetext{
${ }^{9}$ A educação da atenção é silenciosa, como aponta Antonella Tassinari (2015), mas também depende das perguntas do aprendiz. Durante a Tela Indígena, Pedro falava, durante a atividade que participou como convidado, para irmos fazer perguntas a ele. Era importante perguntar e depois ficar pensando em cima, afinal, não era de uma hora para outro que saberíamos as coisas.

${ }^{10}$ Essa mesma história, mas com algumas diferenças, também encontrei em "Educação Escolar Indígenas e/ou Educação indígena: questões e possibilidades para "Kainganguizar" a escola", artigo de Rogério Reus Gonçalves da Rosa e Rojane Brum Nunes (2013). Como aponta Lévi-Strauss (1996), a originalidade do mito, em relação aos outros fatos linguísticos, é que o valor do mito, nas suas mais diversas traduções, persiste.
} 
Pedro: "E o rá tẽj. O kamē, pode notar. Eu tenho notado com os velhos que ele é mais avançado sobre querer tomar o poder".

Eu: "Sim"

Pedro: "O kamē, né. E o kanhru não é tanto. Ele é mais humilde. Só que o kanhru ele é bem-mandado. Quando manda ele, ele faz. O kanhru. Com os velhos eu aprendi dessas partes. A diferença."

Eu: "Mas, então, é por isso que tem que andar junto? Por serem diferentes?

Pedro: "Sim, eles têm que continuar junto igual. Porque eles precisam um do outro. Vamos supor, se tu ganhar uma marca, né: Rá ror. Você tem que conviver mais com rá tẽj. Para disputar as ideias. Porque o rá tęj ele é, já digo assim, avançado. Mais estressado. Ele precisa do rá ror. Porque o rá ror é mais humilde, mais bem-mandado, obediente".

Eu: "Ah, eles vão trocando".

Pedro: "É, dai vão trocando. Eles ajudam um ao outro" (entrevista com Pedro Garcia, novembro de 2018).

O kujá Pedro me colocou a pensar sobre a constituição de um corpo Kaingang a partir da constante transformação na relação com o outro. Os seres que possuem marca Kamē e Kanhru têm características que foram descritas como opostas (VEIGA 2000, ROSA, 2005), mas que, para além da oposição, dependem uma da outra e existem nesse encontro (BAPTISTA DA SILVA, 2002).

Os casamentos ideais são aqueles onde os parceiros possuem marcas contrárias e os filhos possuirão a marca do pai. Assim, o feto se desenvolve em um útero de marca contrária a sua e, após o nascimento, é o leite da mãe que continua fazendo esse corpo crescer.

Marilyn Strathern $(2014 ; 2016)$ propõe pensar o indivíduo não como algo dado a priori, mas como algo que vai se construindo nas suas relações. Fazer essas conexões nos permitiria pensar a pessoa como um todo, ao mesmo tempo que sempre menos do que um, como também nos permitiria pensar que a educação como a constituição de um corpo (seja ele kamē ou kanhru) pode ser compreendido como um processo contínuo de transformação e manutenção. Como aponta Clementine Márechal (2015), as metades kamēe kanhru, rá tēje re ror, são fluídas.

Se eu ganhar uma marca rá ror, como disse Pedro, eu preciso conviver com rá tēj. Afinal, se o sol mata, a chuva traz vida. Nessa história do sol e da lua, podemos entender essa diferença como sendo tanto oposição, quanto fertilidade. Ter uma marca é ter características específicas, que definem como os diferentes seres (sejam eles humanos ou não humanos) agem no mundo. É na convivência com o outro - nesse ir trocando e se ajudando - que os corpos Kaingang têm, dentro de si, as duas metades (MARÉCHAL, 2015), mesmo que seja uma que prevaleça.

Assim, conhecer, ter, adquirir, fazer sabedoria - êg jykre - acontece a partir da relação com a diferença. Aquele que é Kanhru, como colocou Pedro, ensina aquele que é kamē a agir de modo que ele não agiria e vice-versa. Eles debatem suas ideias e vão trocando, ajudando um ao outro. Assim, a diferença é potência e a transformação é a constância. Nunca se para de aprender, pois durante toda a vida é possível conhecer algo diferente daquele que possui 
outra marca A pessoa está sempre sendo feita e refeita a partir das suas relações, um ser ligado a relações externas que olha para fora, para as suas conexões que são cultivadas (STRATHERN, 2016).

\section{A UNIVERSIDADE É KAMË}

Ninguém consegue escapar da educação. Tudo o que fazemos está entrelaçado a ela, existindo a todo momento e em todas as sociedades. Ou melhor: as educações, como pontua Carlos Rodrigues Brandão (1995). Рara o autor, se a educação é universal, os modos de organizá-la e efetivá-la, bem como os significados e objetivos atribuídos, são peculiares a cada grupo social sendo este um dos mecanismos de que os homens lançam mão para criar guerreiros ou burocratas (BRANDÃO, 1995). Nas sociedades Kaingang, como venho aprendendo com os meus interlocutores, para aprender é preciso estar em contato com o mundo. Experimentar. Perceber. Sentir. Êg jykre se fazem com o outro.

Para Rogério Rosa e Rojane Nunes (2013), na lógica dos coletivos ameríndios, a educação significa o meio pelo qual as suas práticas culturais, as suas relações cosmológicas e mitológicas perduram no tempo. Com isso, primeiro pontuo, como aponta Sergio Baptista (2002), que o dualismo que constitui a sociabilidade Kaingang abrange e engloba todo o cosmos (as pessoas, as árvores, os animais, as comidas), dando características específicas de conhecer e estar no mundo a todos esses seres que possuem marca (características físicas, emocionais e psicológicas), como trazido por Pedro através da imagem de força do Sol e da Lua e como será abordado por Angélica a seguir. Após, levo o leitor à Tupã Nhe Kretã para conhecer histórias que falam sobre a possibilidade de aprender com os seres que não são exclusivamente os seres humanos e que, a priori, não fazem parte do cosmos kaingang.

Era noite. Eu e a Angélica estávamos sentadas no sofá da casa. Eu servia o chimarrão e Aline, sua irmã, fritava "aqueles bolinhos dos Guarani", como mais cedo chamaram. Eu conversava com Angélica sobre a minha dissertação, relembrando as vivências que tive na caminhada junto com ela e que pensava essas experiências a partir da episteme de conhecimento dos Kaingang. A partir do Kamē e do Kanhru. Queria saber a sua opinião até porque percebia uma relação forte de amizade e aprendizado entre ela e a Iracema, que também é Kanhru ${ }^{11}$.

\footnotetext{
${ }^{11}$ A relação entre pessoas da mesma marca é nomeada como regré. Dediquei um capítulo específico na minha dissertação para pensar sobre esta relação.
} 
"Sabe Gê, com kamēé diferente", ela dizia. "Aquelas histórias que tu conhece ${ }^{12}$, isso nunca aconteceria com uma mulher kamē. Os kamētem algo mais físico. De atuação na hora. Uma maior imposição nos lugares". Me recordo que ela comentava enquanto eu anotava no meu caderno amarelo. Acabei de tomar meu chimarrão, servi outro e passei para ela. Me acomodei no sofá, sentando em cima da perna esquerda e apoiando meu caderno no braço esquerdo do sofá.

"Falta, talvez, eu conviver mais com uma mulher kamē para aprender a ser mais assim". Ela continuou. "Mas as coisas vão acontecendo de uma forma específica para a gente aprender. E a Universidade, o tempo todo, colocava em evidência o meu modo de vida... e daí eu tinha que, mesmo sem convite, me posicionar".

Conversando nesta noite a Angélica trouxe à tona a possibilidade de pensar a universidade como um ser que, na relação com ela, possui marca kamē. A marca cumprida é relacionada ao irmão kamē, que é o lado do sol e com características que falam sobre a sua agilidade e imposição. Como ensinou Pedro, é com a marca contrária que a gente aprende (briga, briga, briga, mas se acerta). O Sol, impositivo, querendo demarcar seu poder faz relação aqui com a universidade. Uma mulher kamē, na convivência, também agiria dessa forma e ensinaria esse modo de reação, mas na sua trajetória (e porque "as coisas vão acontecendo de uma forma específica para a gente aprender"), foi outro ser kamē que assumiu este lugar.

Nesta conversa na Tupa Nhe Kreta, Angélica me falou sobre a alma deste corpo que impõem suas regras. Um corpo que é a instituição, as burocracias, o modo de vida, de ser e estar na cidade. Que é um emaranhado de práticas que se impõem como hegemônicas. Um corpo que se mostra kamē diante do seu corpo kanhru, que age e que sente de um determinado modo quando na relação com o mundo. Assim, a universidade se apresenta como kamē porque na violência de impor um modo de vida e aprendizagem ensina que ela também precisa se impor. A relação com a outra marca (ou seja com outra potência, com outra perspectiva), realiza a manutenção do corpo de potência oposta. Só sol e só chuva, causa danos, como ensina Pedro. E assim, do nascimento à morte, a partir das diferentes experiências com todos os seres do cosmos, o corpo está em constante construção, mantendo em si a harmonia das diferentes marcas.

Depois daquele encontro, fiquei refletindo sobre a ideia de que se a universidade possui marca, ela também possui um tãn (alma/potência). Foi por isso que, em março de 2019, no encontro do núcleo da UFRGS da Ação Saberes Indígenas na Escola, perguntei

\footnotetext{
${ }^{12}$ Aqui a Angélica está se referindo a episódios em que foi abordada por servidores e professores que questionavam o fato de sua filha estar junto a ela.
} 
sobre a potência da universidade ao Jorge Garcia, o pajé mais velho do Povo Kaingang (pai do kujá Pedro).

Ele falava sobre a ajuda da UFRGS ser forte. Sobre a importância do conhecimento dos kujá ir para o papel. Sobre como a escola entrou na sua vida e sobre como ele começou a pesquisar a escola. Depois começou a dizer que tudo tinha um dono. "Os tãn?", perguntei sem ser ouvida por ele, mas sendo ouvida pela kujá Iracema que respondeu acenando positivamente com a cabeça. "De tudo quanto é coisa tem um mestre. O Sol, a Lua, as estrelas. Até uma casa". Ele dizia. "A Universidade também tem um mestre?", perguntei, dessa vez, sendo ouvida. "Claro! Não tem gente que manda lá?".

Entendo que a noção de socialidade permite pensar conceitualmente o processo de aprendizagem a partir de relações que se estabelecem com todos os seres, sejam eles humanos ou não humanos, que formam (transformando constantemente) corpos. Conforme Villaça (2005), enquanto a antropologia clássica nos forneceu uma noção de estrutura social como um sistema de relacionamentos entre grupos, os ameríndios apresentam princípios estruturais baseados em sistemas de relacionamentos entre corpos (VILLAÇA, 2005 apud SEEGER; DA MATTA; VIVEIROS DE CASTRO 1979, p.446).

O conceito de entidade mestra é utilizado pelos Kaingang para se referir à potência dos animais e das plantas e pode ser traduzido como tãn (CRÉPEAU, 2015). Mestre, entidade mestra, dono seriam possíveis traduções para tãn e, na linguagem Kaingang, tãn é usado como sufixo sendo adicionado ao final das palavras para se referir à entidade mestra de determinado ser. Aquele que "manda" naquele corpo, como falou Jorge. Por exemplo: gójé água e gójtãn, seria a dona da água, a mestra da água.

Crépeau (2015) escreve que a morte de um animal, o abate de uma árvore ou a colheita de uma planta medicinal implicam uma relação com uma entidade tãn que torna possível e legítimo o ato de predação e apropriação. Para isso, há uma forma de se portar diante destes seres tendo em vista que cada uma dessas entidades possui não só características particulares, como um poder muito grande.

Eu e a Aline ouvíamos Angélica refletir sobre suas experiências. Já era noite e fazia um pouco de frio. Entre uma cuia de chimarrão e um bolinho frito, ficamos muito tempo conversando. "A gente vai para as nossas aldeias descansar, mas esses espaços precisam da gente. Eu sempre falo para as meninas lutarem, porque a Universidade te doma", continuava a nos falar. "A todo momento estão querendo embranquecer a gente. Seja na cor, seja na mente, mas o nosso modo é bonito e temos que passar isso para as nossas crianças".

Strathern (2016) aponta que seres radicalmente distintos podem se transformar uns nos outros e a Angélica pontua às suas irmãs que a potência da Universidade pode domar e, por isso, a relação deve ser cautelosa. As marcas kamēe kanhuru não estão fixas nos corpos. 
Рara compreender a universidade como um ser forte (possível de domar, como também de ajudar, como pontua Angélica e Jorge), é preciso dar vida de volta a ela. Considerar as estruturas de ensino que ainda estão colocadas em torno da transmissão de conhecimento científicos, tecnológicos e humanistas que foram padronizadas nas instituições de ensino ocidentais a partir da reforma epistêmica (CARVALHO; FLÓREZ, 2014) e se perpetuam ainda hoje. Por outro lado, seja através da vida cotidiana (levando, por exemplo, para esse espaço as crianças e os mais velhos), como também através da produção do seu conhecimento "ao modo fóg" (através de artigos, livros, trabalhos de conclusão, dissertações e teses) que a presença das pessoas indígenas transforma esse espaço.

Assim, o tãn da universidade também é suscetível de transformação a partir dos fluxos de vida que, a partir das políticas afirmativas, passam a habitá-la especificamente no lugar de alunos. Pensar a Universidade como um ser kamē permite refletir que esse corpo possui alma/potência e, portanto, é suscetível à transformação a partir do contato com a luta dos estudantes indígenas, que dão continuidade à luta das suas lideranças.

\section{CONSIDERAÇÕES FINAIS}

Contei ao leitor, através de uma etnografia que costurou diferentes locais, encontros que me fizeram refletir sobre a aprendizagem a partir da episteme do Povo Kaingang. Talvez deixar-se afetar, no sentido de transformar-se, deva começar pelo próprio método que buscamos seguir quando queremos aprender sobre algo. Pensando isso no meu caso, eu traduziria num imperativo: se quer aprender sobre educação desde a perspectiva kaingang, eduque-se!

Caminhei junto à Angélica em diferentes cidades, retomadas e territórios indígenas demarcados. As pessoas indígenas estão circulando por todos os territórios. É triste ter que reafirmar o óbvio, mas me parece sempre importante lembrar o que aprendi. Ser indígena é simplesmente ser. Existir. Não se deixa de ser indígena por viver na cidade.

Neste artigo, trouxe uma etnografia e uma discussão que buscam ampliar as noções de aprendizagem para além da sala de aula e que acontece na relação com todos os seres do cosmos. Se ir para a universidade é uma forma de continuar caminhando pelo território como antigamente se fazia - estar na universidade é aprender a estrutura de pensamento do não indígena, como também aprender com o tãn da instituição. Relacionar-se tão diretamente com essa perspectiva de conhecimento que se tornou mundialmente hegemônica e que ainda coloniza e sobrepõem as demais (QUIJANO, 2005), é perigoso. O inimigo pode te domar. Ao aprender sua perspectiva, você pode se transformar nele.

Porém, para o caçador anteceder à presa, precisa se submeter aos modos como entende saúde, educação, justiça, o corpo, o território. Como colocou a liderança Kaingang 
Eli durante a III Tela Indígena (2018), os jovens relacionam-se com o inimigo agora ainda mais de perto que antigamente, pois frequentam as suas instituições de formação superior. Submetem-se ao modo de vida dos fóg, adquirindo sua perspectiva, fazendo aliados e retornando aos seus territórios para fortalecer a luta do seu povo.

Importante refletir, do mesmo modo, que não necessariamente a universidade será sempre kamē. Como ensinam os kujá as marcas não estão fixas nos corpos. Afinal, a consequência da Universidade te domar não seria a transformação? Alerta que a Angélica faz às suas irmãs. Isso nos leva a duas questões. A primeira, e que logo retomo, é que a instituição também pode se transformar. E a segunda é a possibilidade de pensar aprendizagem como transformação.

A ideia de ser preciso se transformar em outro para ser tu mesmo, como traz o título, busca justamente sugerir que para aprender é preciso estar em movimento e lidar com o contexto no qual se está participando, como aponta Lave (2015). É também nesse sentido que a universidade se apresenta como um ser kamē. É na relação com uma mulher indígena que a colonialidade instituinte na academia se faz perceber e nesta violência de impor um modo de aprender e estar, ela ensina a Angélica, uma mulher kanhru, que ela também precisa impor o seu modo de vida e conhecimento. Estar na universidade não aparece como um ato que tem um só fim (formar-se no curso, por exemplo), mas como mais um local onde pessoas indígenas Kaingang vão passar e se relacionar: para modificar-se, com todo o conhecimento que pode ser adquirido ao frequentar um determinado curso, mas também para modificar esse espaço, o que nos leva de volta à primeira questão pontuada acima.

Como trazido por Crépeau (2015), a morte de um animal ou abate de uma árvore implica uma relação com uma entidade tãn, tornando possível o ato de predação e apropriação. Nesse sentido, olhar para a universidade como um ser kamēé perceber que há uma potência (aqui entendida como tãn) que perpassa todos os seres do cosmos sejam eles humanos ou não humanos. Pensar que o tãn da universidade também pode se transformar é perceber que as mesmas instituições que apagaram histórias e ciências, agora formam autores indígenas que produzem desde outra perspectiva. É como a imagem do veneno da serpente, que pode ser o veneno e o remédio. Como pontou Nyg Kuitá Kaingang, em live de lançamento do caderno "Universidade Território Indígena!"13, há um duplo significado dos estudantes indígenas estarem na universidade. Trata-se de transformar um histórico de

\footnotetext{
${ }^{13}$ O caderno "Universidade Território Indígena!", produzido pelo Conselho de Missão Entre Povos Indígenas (COMIN), foi lançado no dia 24 de fevereiro de 2021 e teve a participação dos autores indígenas que colaboraram na produção do material. A live está gravada e pode ser assistida no canal do youtube do COMIN.
} 
violência, mas também contribuir para o mundo com o seu conhecimento e para a construção de uma universidade plural.

A etnografia trazida também demonstra que a educação, em uma episteme que se atenta a todos os seres do cosmos - humanos, animais, vegetais, as instituições de ensino -, amplia os espaços de ensino para além da sala de aula, como também amplia a noção de que aprender estaria relacionado a um período da vida ou a um currículo pré determinado. A ideia aqui não é negar a importância do aprendizado que acontece a partir das instituições de ensino, mas ampliar essa perspectiva para outras possíveis.

É nesse sentido que percebo a demanda da Casa de Estudante Indígena. Essa demanda não parece falar apenas sobre uma questão de moradia - principalmente das mães indígenas que, normalmente, trazem seus filhos para viver com elas na cidade. Essa demanda também coloca em questão e reinvindica a ampliação dos espaços de educação da pessoa indígena. Reivindica que diferentes formas de ensinar e aprender podem coexistir. A kujá Iracema pontua que é necessário ter um espaço para receber tanto um kujá kamē, como um kujá kanhuru. Um local onde se possa fazer determinadas comidas e rituais.

Essa é uma demanda que, conforme Iracema, é pontuada desde o início do processo de luta pela abertura de vagas. Mesmo não existindo esse espaço (e as mães todos os semestres de curso enfrentarem problemas para estar com as crianças), as crianças não deixam de estar na universidade. Da mesma forma, mesmo não existindo esse espaço, a kujá Iracema não deixa de frequentar os eventos organizados pelos jovens ou realizar visitas para banhar as mulheres grávidas. Nesse sentido, a produção acadêmica de autores indígenas somada à presença resiliente de jovens, adultos, anciãos e crianças neste local parecem subverter a colonialidade instituinte da academia. Não parece ser uma luta que nega a força do inimigo, pelo contrário, é uma luta que abraça e utiliza a perspectiva do inimigo. A ajuda da universidade é forte, me pontou o kujá Jorge Garcia. E agora, mais do nunca, os estudantes indígenas podem experimentar e se apropriar desta força em prol do seu povo.

Não foi fácil retornar à ideia de aprender em movimento neste momento de isolamento social em função da pandemia do Covid-19 que o Brasil e o mundo estão vivendo. Fiquei me perguntando sobre a própria ideia de deslocamento. Caminhar tem a ver com deslocamento físico, mas também tem a ver com um pensamento caminhante. Atualmente, os estudantes indígenas passam por outros desafios e, através da produção de livros ${ }^{14}$, artigos e lives, novas questões vêm sendo colocadas. É preciso lidar com a pandemia no seu

\footnotetext{
${ }^{14}$ O livro "Políticas Indigenistas, contribuição para afirmação e defesa dos direitos indígenas" (2020), organizado pela Dra. Rosa Maria Castilhos Fernandes e pela Mestranda em Serviço Social da UFRGS Angélica Domingos Kaingang, foi escrito e lançado durante a Pandemia do Covid-19 e reúne autores indígenas e não indígenas. O livro lançou um grande desafio a esses escritores indígenas e não indígenas que construíram seus textos e reflexões sem poder se encontrar presencialmente uma única vez. Tive o prazer de escrever ao lado de Aline Domingos Kaingang e Kate Lima Tikuna.
} 
território e cumprir com os deveres de sala de aula. Aprender com os professores e, também, demarcar seus conceitos. O mundo parece estar, mais do que nunca, parado e em movimento.

Com estas reflexões, espero ter contribuído quanto às diferentes formas de aprender e fazer conhecimento que circulam de forma intensa dentro das instituições de ensino superior. Espero ter contribuído no pensamento de que as políticas afirmativas são uma oportunidade para a construção de uma universidade plural que abre suas portas, reconhece e afirma - no seu quadro de alunos e de professores, na sua estrutura, nos currículos dos cursos - as diferentes ciências.

A diferença importa. Ela nos desloca de nós. Mostra outro ângulo do que pensávamos conhecer. Como vimos, o conhecimento, êg jykre, sempre se faz com o outro. Nunca sozinho.

\section{REFERÊNCIAS}

ABU-LUGHOD, Lila. Locating Ethnography. Ethnography, v., n. 2, p. 261-267, 2000.

BAPTISTA DA SILVA, Sergio. Dualismo e cosmologia Kaingang: 0 xamã e o domínio da floresta. Horizontes Antropológicos, v. 8, n. 18, p.188-209, 2002.

BAPTISTA DA SILVA, Sergio. Cartografia Sociocultural de espaços e práticas educativos ameríndios: refletindo sobre a indigenização da escola. Horizontes Antropológicos, v. 7, n. 2, p. 227-238, 2013.

BRANDÃO, Carlos Rodrigues. 0 que é Educação? São Paulo: Brasiliense, 1995.

CARVALHO, José Jorge; FLÓREZ FLÓREZ, Juliana. Encuentro de Saberes: Proyecto para decolonizar el conocimiento universitário eurocéntrico. Nómadas, n. 41, p. 131-147, 2014.

CRÉPEAU, Robert R. Les Substances du Chamanisme Perspectives sud-amérindiennes. Anthropologie et Societés, v. 31, n. 3, p. 107-125, 2007.

CRÉPEAU, Robert R. Les animaux obéissent aussi à la religion. Paradoxes du chamanisme Kaingang (Brésil) en contexte pluraliste. Anthropologie et Societés, v. 39, n 1-2, p. 229-249, 2015.

FERNANDES, Rosa Maria Castilhos; DOMINGOS, Angélica. Políticas Indigenistas: contribuições para afirmação e defesa dos direitos indígenas. Porto Alegre: Editora da UFRGS/CEGOV, 2020.

FONSECA, Claudia. Lá onde, cara pálida? Pensando as glórias e os limites do "campo etnográfico". In: BRITES, Jurema; MOTTA, Flávia de Mattos. Etnografia, o espírito da Antropologia. Tecendo linhagens. Homenagem a Claudia Fonseca. 1. ed. Santa Cruz do Sul: EDUNISC, 2017. p. 438-466.

GOLDMAN Marcio. Os tambores dos mortos e os tambores dos vivos: etnografia, antropologia e política em Ilhéus. Revista de Antropologia,v. 46, n. 2, p. 423-444, 2003. 
GOMES, Ana. Arguição feita à dissertação de Ana Letícia Meira Schweig, "A educação pela terra Professores Kaingang, territorialidade e políticas estatais, PPGAS, 2018.

IBGE - INSTITUTO BRASILEIRO DE GEOGRAFIA E ESTATÍSTICA. Censo Demográfico 2010 - Características Gerais dos Indígena. Resultados do Universo. Censo demográfico, Rio de Janeiro, p.1-245, 2010.

INGOLD, TIM. Da transmissão de representações à educação da atenção. Educação, v. 33, n. 1, p. 6-25, 2010.

INGOLD, Tim. 0 dédalo e o labirinto: caminhar, imaginar e educar a atenção. Horizontes Antropológicos, v. 21, n. 44, p. 21-36, 2015.

INGOLD, Tim. Chega de etnografia! Educação, v. 39, n. 3, p. 404- 411, 2016.

LANGDON, Esther Jean. Xamãs e xamanismos: reflexões autobiográficas e intertextuais sobre a antropologia. ILHA, v. 11, n. 2, p.162 - 191, 2010.

LAVE, Jean. Aprendizagem como/na prática. Horizontes Antropológicos, v. 21, n. 44, p. 37-48, 2015.

LÉVI-STRAUSS, Claude. A estrutura dos mitos. In: LÉVI-STRAUSS, Claude. Antropologia estrutural. Rio de Janeiro, Tempo Brasileiro. 5. ed., Cap. XI, 1996. p. 237-265.

MABILDE, Pierre F. A. Booth. Apontamentos sobre indígenas selvagens da nação Coroados dos matos da província do Rio Grande do Sul: 1836-1866. São Paulo: Ibrasa; Brasília: INL, 1983.

MARÉCHAL, Clémentine. Eu luto desde que me conheço como gente: Territorialidade e cosmopolítica Kanhgág enfrentando o poder colonial no sul do Brasil. Dissertação (Mestrado). Universidade Federal do Rio Grande do Sul, Instituto de Filosofia e Ciências Humanas, Programa de Pós-Graduação em Antropologia Social, 2015.

MARCUS, George E. Etnografía en/del sistema mundo. El surgimiento de la etnografía multilocal. Alteridades, v. 11, n. 22, p. 111-127, 2001.

PÉTONNET, Colette. Uma entrevista com Colette Pétonnet. [Entrevista concedida a Revue Urbanism]. Thierry Paquot com colaboração de Claudia Fonseca. In: BRITES, Jurema; MOTTA, Flávia de Mattos. Etnografia, o espírito da Antropologia: Tecendo Linhagens homenagem a Claudia Fonseca. 1. ed. Santa Cruz do Sul: EDUNISC, 2017. p. 426-437.

QUIJANO, Anibal. Colonialidade do poder, Eurocentrismo e América Latina. In: LANDER, Edgardo. A colonialidade do saber: eurocentrismo e ciências sociais. Perspectivas latino-americanas. Buenos Aires: CLACSO, 2005. p. 117-142.

ROSA, Rogerio Reus Gonçalves da. Os kujá são diferentes: um estudo etnológico do complexo xamânico dos Kaingang da terra indígena Votouro. Tese de Doutorado - Curso de Antropologia Social, PPGAS/UFRGS, Porto Alegre, 2005.

ROSA, Rogerio Reus Gonçalves da; NUNES, Rojane Brum. Educação escolar indígena e/ou educação indígena: questões e possibilidades para "kainganguizar" a escola. Século XXI. Revista de Ciências Sociais, v.3, n. 1, p. 88-119, 2013. 
SAMPAI0, Osias Awá-Mboparadjú Guarani Ramos. A universidade como área de influência, no olhar de um guarani. Iluminuras, v. 18, n. 43, p. 134-157, 2017.

SCHWEIG, Ana Letícia. A educação pela terra: professores Kaingang, territorialidades e políticas estatais. Dissertação de Mestrado - Universidade Federal do Rio Grande do Sul, Instituto de Filosofia e Ciências Humanas, Programa de Pós-Graduação em Antropologia Social, Porto Alegre, 2018.

STRATHERN, Marilyn. Fora de contexto: as ficções persuasivas da antropologia (seguido de comentários e resposta). In: STRATHERN, Marilyn. 0 efeito etnográfico e outros ensaios. São Paulo: Terceiro Nome, p. 27-85, 2013. p. 159-209.

STRATHERN, Marilyn. A pessoa como um todo e seus artefatos. In: STRATHERN, Marilyn. 0 Efeito etnográfico e outros ensaios. São Paulo: Cosac Naify, 2014. p. 487-509.

STRATHERN, Marilyn. Revolvendo as raízes da antropologia: algumas reflexões sobre "relações". Revista de Antropologia, v. 59, n. 1, p. 224-257, 2016.

UFRGS, Universidade Federal do Rio Grande do Sul. Relatório anual do programa de ações afirmativas. Porto Alegre/Rio Grande do Sul, 2016.

TASSINARI, Antonella. Produzindo corpos ativos: a aprendizagem de crianças indígenas e agricultoras através da participação nas atividades produtivas familiares. Porto Alegre, v. 21, n. 44, p. 141-172, 2015.

VEIGA, Juracilda. Cosmologia e práticas rituais Kaingang. Campinas: Unicamp. Tese (Doutorado) Curso de Antropologia Social. PPGAS/Universidade de Campinas, 2000.

VILLAÇA, Aparecida. Chronically unstable bodies. Journal of the Royal Anthropological Institute, n. 11, p. 445-464, 2005.

WAGNER, Roy. A presunção da cultura e A cultura como criatividade. In: WAGNER, Roy. A invenção da cultura. São Paulo: Ubu Editora, 2017 [1975].

WAGNER, Roy. A invenção da Antropologia - Roy Wagner e a Revolução nos modos de pensar. Folha de São Paulo. Ferrari, Florencia; Dulley, Iracema; Pinheiro, Jamille; Valentini, Luísa; Sztutman, Renato e Marras, Stelio. Entrevista. Folha de São Paulo. Abril, 1, 2012.

Recebido em 29 de junho de 2020. Aprovado em 01 de fevereiro de 2021. 